Nutrition Research and Practice (Nutr Res Pract) 2012;6(5):474

http://dx.doi.org/10.4162/nrp.2012.6.5.474

pISSN 1976-1457 eISSN 2005-6168

\title{
Erratum: Funding Acknowledgment
}

Ji-Hye Jung, Ji-In Kang, Hyun-Sook Kim

To the Editor:

We found an error in our published article:

Ji-Hye Jung, Ji-In Kang, Hyun-Sook Kim. Effect of quercetin on impaired immune function in mice exposed to irradiation. Nutr Res Pract 2012;6:301-307. http://dx.doi.org/10.4162/nrp.2012.6.4.301

The funding acknowledgment in this article was omitted as published.

Additional acknowledgment is as follow:

This work was supported by the Sookmyung Women's University Research Grants 2010 and also supported by BK21.

The authors apologize for any inconvenience this mitake may have caused. 